\title{
Оценка эффективности и безопасности омализумаба в комплексной терапии больных с тяжелой неконтролируемой атопической бронхиальной астмой в течение 12 месяцев наблюдения
}

ФГУ НИИ пульмонологии ФМБА России: 105077, Москва, ул. 11-я Парковая, 32, к. 4

\author{
Yu.B.Suchkova, G.L.Osipova, A.G.Chuchalin, T.L.Pashkova
}

\section{Assessment of efficacy and safety of omalizumab in therapy of patients with severe uncontrolled atopic bronchial asthma during 12-month follow-up}

\begin{abstract}
Summary
This was a 12-month trial on efficacy and safety of treatment with omalizunab of 46 patients with severe uncontrolled atopic asthma. The patients were divided into 2 groups: the $1^{\text {st }}$ group received omalizumab and a standard basic therapy, the $2^{\text {nd }}$ group was treated with the standard basic therapy without omalizumab. A frequency of daytime and nighttime symptoms, need in relief medications, daily dose of inhaled steroids (ICS) in beclomethasone dipropionate equivalence, exacerbation rate, hospitalization rate, unscheduled visits to a physician due to asthma, quality of life (using the AQLQ questionnaire), and spirometric parameters were analyzed. The asthma control was evaluated according to GINA, 2006. The treatment resulted in statistically significant improvement in daytime and nighttime asthma symptoms, reduction in need in short-acting $\beta_{2}$-agonists and daily doses of ICS, rates of asthma exacerbations, hospitalizations and unscheduled visits to a physician due to asthma in the $1^{\text {st }}$ group patients compared to the baseline values and to the $2^{\text {nd }}$ group. Quality of life and lung function also significantly improved in the $1^{\text {st }}$ group. Adverse events in the patients treated with omalizumab were as frequent as those in the control group and did not require withdrawal of the treatment. Therefore, addition of omalizumab to the standard basic therapy in severe uncontrolled atopic asthma allowed successful improvement the control of the disease and the patients' quality of life, reduction in the daily dose of ICS.
\end{abstract}

Key words: severe uncontrolled bronchial asthma, omalizumab, AQLQ.

\section{Резюме}

Было проведено 12-месячное исследование эффективности и безопасности применения омализумаба (Ксолар) у больных с тяжелой неконтролируемой атопической бронхиальной астмой (БА). В исследовании принимали участие 46 больных. Пациенты были распределены на 2 группы. 1-я группа получала омализумаб в дополнение к базисной терапии, 2-я группа (сравнения) получала только базисную терапию. В ходе исследования анализировались такие показатели, как частота дневных и ночных симптомов, потребность в препаратах неотложной помощи, суточная доза ингаляционных глюкокортикостероидов (иГКС) в пересчете на беклометазона дипропионат, частота обострений и госпитализаций, внеплановых визитов к врачу, качество жизни (по опроснику AQLQ), показатели спирометрии. Уровень контроля БА определялся согласно критериям GINA 2006 г. В ходе исследования в 1-й группе больных наблюдалось статистически значимое, по сравнению с исходными показателями и показателями во 2-й группе, снижение частоты дневных и ночных симптомов БА, потребности в ингаляциях $\beta_{2}$-агонистов короткого действия, суточной дозы иГКС, частоты обострений БА, госпитализаций и числа внеплановых визитов к врачу. Отмечено также статистически значимое улучшение показателей качества жизни, по опроснику AQLQ, и показателей функции внешнего дыхания у больных 1-й группы. Нежелательные явления, отмеченные в ходе исследования в группе пациентов, получавших лечение омализумабом, были сравнимы с нежелательными явлениями в группе контроля и не потребовали отмены препарата. Таким образом, добавление омализумаба к базисной терапии больных с тяжелой неконтролируемой атопической БА позволяет эффективно улучшить контроль над заболеванием, снизить суточную дозу иГКС, а также улучшить качество жизни пациентов. Ключевые слова: тяжелая неконтролируемая бронхиальная астма, омализумаб, AQLQ.

Бронхиальная астма (БА) представляет собой серьезную глобальную проблему здравоохранения, имеюшую большое социально-экономическое значение [1], и является одной их главных причин заболеваемости и смертности во всем мире. Ежегодно от БА умирают $>200$ тыс. человек [2], что свидетельствует о недостатке адекватного контроля над этим заболеванием.

БА является хроническим воспалительным заболеванием дыхательных путей, в котором принимают участие различные клеточные элементы. Специфическая клиническая симптоматика (повторяющиеся эпизоды экспираторной одышки, свистящих хрипов, чувства заложенности в грудной клетке, кашля) обу- словлена развитием распространенной, но изменяющейся бронхиальной обструкции, носящей обратимый характер [2, 3]. Независимо от степени тяжести заболевания воспаление в дыхательных путях является персистирующим и координируется Т-лимфоцитами-хелперами II типа, которые синтезируют цитокины (интерлекины 4, 5 и 10), отвечающие за пролиферацию эозинофилов и созревание тучных клеток, а также за синтез иммуноглобулина G (IgE) B-лимфоцитами. Молекулы IgE в последующем связываются с Fсع RI-рецепторами тучных клеток, и при их соединении с аллергеном происходит высвобождение медиаторов и возникает характерная клиническая 
симптоматика аллергического заболевания. Имеется взаимозависимость между уровнем циркулирующего IgЕ и симптомами БА: у пациентов с атопической БА уровень IgЕ часто повышен [2, 4].

Препараты для лечения БА традиционно делятся на 2 группы. К 1-й группе относят лекарственные средства базисной, контролирующей течение заболевания терапии (глюкокортикостероиды (ГКС), кромоны, антилейкотриеновые препараты), во 2-ю группу входят $\beta_{2}$-агонисты короткого и длительного действия, метилксантины, М-холиноблокаторы. В настоящее время общепринятым является ступенчатый подход к лекарственной терапии БА в зависимости от уровня контроля заболевания [2].

Предупреждение аллерген-индуцированного высвобождения медиаторов воспаления из клеток-мишеней составляет основу новой стратегии терапии атопических болезней $[5,6]$. Лечение аллергических заболеваний, включая аллергическую БА, было усовершенствовано благодаря разработке препарата омализумаб (Ксолар, "Новартис Фарма") - рекомбинантных гуманизированных моноклональных анти-IgE (IgG1) антител, которые избирательно связываются с IgE человека. Омализумаб связывается с циркулирующими в крови $\mathrm{IgE}$, тем самым блокируя его последующее взаимодействие с высокоафинными рецепторами Fce RI на поверхности тучных клеток, уменьшая дегрануляцию последних и высвобождение медиаторов. Препарат не способен непосредственно связываться с FceRI-рецепторами, локализованными на тучных клетках. Кроме того, весьма важным в клиническом отношении является свойство омализумаба уменьшать плотность рецепторов IgE на поверхности многих клеток (тучных, дендритных) [7], что также ослабляет провоспалительное действие $\operatorname{IgE~[8].~Дополнительным~механизмом,~}$ обеспечивающим противовоспалительный эффект омализумаба, может являться и усиление апоптоза эозинофилов, за счет которого происходит снижение их числа [9].

Фармакокинетика и фармакодинамика препарата были многократно изучены ранее [10]. Примерно у 3 \% пациентов, получавших лечение омализумабом, после введения 1-й дозы развивались уртикарные реакции. В большинстве случаев эти реакции были спонтанными и не повторялись при введении повторных доз препарата. На основании этих результатов, предшествующих доклиническим исследованиям, опасность для пациента расценивается как минимальная.

За последнее 10-летие было проведено много клинических исследований, демонстрирующих положительный эффект терапии омализумабом у больных с неконтролируемой атопической БА среднетяжелого и тяжелого течения. Показано, что лечение моноклональными анти-IgE антителами уменьшает количество обострений БА, позволяет снизить дозу ГКС, применяемых в качестве поддерживающей терапии, а также сократить потребность в препаратах неотложной помощи [10-12]. Существующий опыт клинического использования омализумаба показы- вает, что он является относительно безопасным. Описаны такие нежелательные эффекты данного препарата, как инфекции верхних дыхательных путей, синуситы, фарингиты, головная боль, гельминтные инвазии [13], местные реакции на его введение (боль, гиперемия, отечность). Риск возникновения анафилактических реакций включен в описательную информацию об омализумабе. Имеются сведения о том, что омализумаб-индуцированная анафилаксия может характеризоваться замедленным началом и длительным развитием симптомов, о чем необходимо помнить при назначении препарата [14].

Омализумаб - препарат для длительной терапии атопической БА [15]. Он эффективно понижает уровень свободного IgE, уменьшая выраженность симптомов заболевания, а также снижает местную реактивность при проведении кожных аллергологических тестов. Однако при снижении дозы препарата или после его полной отмены эти показатели могут возвращаться к исходному уровню [16].

Несмотря на высокую стоимость лечения, назначение омализумаба позволяет существенно снизить затраты, связанные с повышенной потребностью в препаратах неотложной помощи, частыми госпитализациями, внеплановыми визитами к пульмонологу и применением высоких доз ингаляционных глюкокортикостероидов (иГКС) [17].

Впервые в России с целью изучения при длительном наблюдении эффективности и безопасности омализумаба и оценки качества жизни больных было проведено открытое сравнительное проспективное 12-месячное исследование в параллельных группах.

\section{Материалы и методы}

В клиническом исследовании участвовали 46 пациентов с тяжелой неконтролируемой атопической БА. Критериями включения были: возраст $>18$ и $<75$ лет, содержание общего $\operatorname{IgE}$ в сыворотке крови $>30$ и $<700 \mathrm{ME/мл,} \mathrm{положительные} \mathrm{кожные} \mathrm{тесты} \mathrm{к} \mathrm{бы-}$ товым и эпидермальным аллергенам, подтвержденная данными спирографии бронхиальная обструкция, носящая обратимый характер (объем форсированного выдоха за 1-ю с $\left(\mathrm{OФB}_{1}\right) \leq 80 \%$ и его прирост $\geq 12 \%$ от исходного уровня после пробы с 400 мкг сальбутамола), прием высоких доз иГКС в пересчете на беклометазона дипропионат (согласно критериям GINA пересмотра 2006 г.). В исследование не включались пациенты с тяжелыми анафилактическими или анафилактоидными реакциями в анамнезе, тяжелой сопутствующей патологией, в т. ч. злокачественными новообразованиями, с любым другим диагностированным активным заболеванием легких, беременные и кормящие грудью женщины. В дальнейшем пациенты были разделены на 2 группы: группу больных, получавших омализумаб (1-ю), и группу сравнения (2-ю).

У всех пациентов собирали анамнез заболевания, аллергологический анамнез, проводили физикальное исследование, оценивали количество дневных и ночных симптомов в неделю, потребность в пре- 
паратах неотложной помощи в сутки, частоту внеплановых визитов к врачу, госпитализаций и обострений БА в год. Проводилось спирографическое обследование. Все пациенты вели дневники, в которых ежедневно оценивали частоту дневных и ночных симптомов, отмечали частоту использования препаратов неотложной помощи.

Анализ качества жизни пациентов проводился при помощи опросника E.F.Juniper AQLQ (Asthma Quality of Life Questionnaire) [18]. Он содержит 32 вопроса, разделенных по 4 тематическим блокам (критериям): степень выраженности основных симптомов БА, повседневная активность больного, негативное влияние БА на его эмоциональную сферу и степень толерантности респондента к факторам окружающей среды. В качестве субъективной оценки пациентом контроля над заболеванием были использованы показатели теста по контролю БА (тест АСТ ${ }^{\mathrm{TM}}$ ) [19].

Уровень IgЕ определялся методом иммунофлюоресцентного анализа с использованием панели и электродиагностического хемилюминесцентного аппарата CLA (Medland Systems, Нидерланды).

Уровень контроля над заболеванием оценивался согласно критериям GINA 2006 г.

Омализумаб назначался пациентам 1-й группы подкожно в верхнюю треть плеча каждые 2 или 4 нед. Расчет дозы препарата осуществлялся в соответствии с показателями массы тела (кг) и исходным уровнем общего сывороточного IgE. Оценка эффективности и безопасности препарата проводилась через 16 и 32 нед. от начала терапии.

Исследование проводилось в течение 12 мес. в параллельных группах и было открытым, сравнительным, проспективным.

\section{Статистическая обработка данных}

Статистическая обработка полученных данных проводилась с помощью пакета прикладных программ Statistica 6.0. Анализ соответствия вида распределения признака закону нормального распределения проводился с использованием критерия ШапироУилка. Признаки, имеющие нормальное распределение, анализировались при помощи параметрических методов статистики, для анализа признаков, распределение которых было отличным от нормального, использовались непараметрические критерии. Для оценки статистической значимости различий при сравнении 2 не связанных между собой групп применялся критерий Стьюдента и непараметрический критерий Манна-Уитни. Повторные измерения анализировали посредством парного критерия Стью- дента и непараметрического критерия Вилкоксона. Различия считались статистически значимыми при $p<0,05$. Данные представлены в виде $\bar{X} \pm S$; $M e(25-75 \%)$, где $\bar{X}$ - выборочное среднее, $S$ - выборочное среднее квадратичное отклонение, $M e-$ медиана, 25-75 \% - интерквартильный размах (значения 25-го и 75-го процентилей соответственно).

\section{Результаты и обсуждение}

Пациенты находились под наблюдением в период с мая 2008 г. по май 2009 г. В 1-й группе, получавшей омализумаб, было 23 больных, из них 17 женщин и 6 мужчин. Средний возраст пациентов составил $42,91 \pm 10,90$ года, средняя длительность заболевания $-15,05 \pm 7,28$ года. Во 2-ю группу вошли 23 больных, 5 мужчин и 18 женщин (средний возраст $49,8 \pm 13,2$ года, средняя длительность заболевания $14,70 \pm 11,15$ года; табл. 1).

В 1-й группе исходно показатель общего сывороточного IgЕ составил 215,98 \pm 127,30 МЕ/мл, во 2-й $253,08 \pm 141,70$ МЕ/мл. Суточная доза иГКС в пересчете на беклометазона дипропионат в 1-й группе исходно равнялась $1552,1 \pm 534,1 ; 2000$ (1 000-2 000) мКг, во 2-й - $1456,5 \pm 520,3 ; 1500$ (1 000-2 000) мкг. Показатели ОФВ 1 до лечения составили в 1-й группе

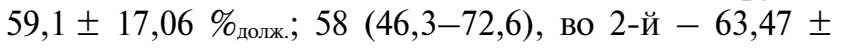

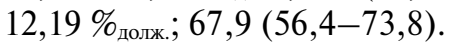

В группе больных, получавших лечение омализумабом, до лечения количество дневных симптомов составляло $6,56 \pm 1,07 ; 7$ (7-7) в неделю, симптомы БА были практически ежедневными, количество ночных симптомов составляло 2,04 \pm 1,55; 2 (1-3) в неделю. У больных отмечалась необходимость частого применения препаратов неотложной помощи для купирования симптомов БА - 5,90 $\pm 2,71 ; 6$ (4-8) вдохов в сутки, частота госпитализаций в год составляла $1,47 \pm 0,84 ; 1(1-2)$, частота внеплановых визитов к врачу - 3,95 $\pm 1,77 ; 4$ (3-5) в год; высокой была частота обострений $-4,39 \pm 2,36 ; 4$ (3-6) в год. Количество баллов по результатам теста по контролю над БА составило исходно 11,40 土 2,67; 11 (9-13). Показатели качества жизни, по данным опросника AQLQ, имели следующие значения: общий балл $3,43 \pm 0,80 ; 3,15(2,9-3,9)$, симптомы БА - 3,3 $\pm 0,8$; $3,27(2,75-3,75)$ балла, ограничение повседневной активности - 3,6 $\pm 0,92 ; 3,36(2,81-4,27)$ балла, эмоциональная сфера - 3,52 \pm 1,15; $3,2(2,8-4,0)$ балла, влияние окружающей среды - 3,30 \pm 1,03; 3 (2,75$3,75)$ балла (табл. 2).

Во 2-й группе частота дневных симптомов в неделю составляла $6,65 \pm 0,71 ; 7$ (7-7), количество ночных

Таблица 1

Характеристика исследуемых групп больных

\begin{tabular}{r|c|c|c|c|c|}
\hline Группы & Число больных & Возраст (лет) & \multicolumn{2}{|c|}{ Пол } & $\begin{array}{c}\text { Средняя продолжительность } \\
\text { заболевания, лет }\end{array}$ \\
\hline 1 -я группа & & & м & ж & $15,05 \pm 7,28$ \\
\hline 2 -я группа & 23 & $42,91 \pm 10,90$ & 6 & 17 & $14,70 \pm 11,15$ \\
\hline
\end{tabular}


Таблица 2

Диналика показателей тестов $A C T$ и $A Q L Q$ у больных, получавших олализумаб

\begin{tabular}{|c|c|c|c|c|c|c|c|c|}
\hline \multirow{3}{*}{ Показатели } & \multicolumn{8}{|c|}{ Периоды наблюдения } \\
\hline & \multicolumn{2}{|c|}{ до начала лечения } & \multicolumn{3}{|c|}{16 нед. } & \multicolumn{3}{|c|}{ 32-44 нед. } \\
\hline & $\bar{X} \pm S$ & $\operatorname{Me}(25-75 \%)$ & $\bar{X} \pm S$ & $\operatorname{Me}(25-75 \%)$ & $p$ & $\bar{X} \pm S$ & $\operatorname{Me}(25-75 \%)$ & $p$ \\
\hline Тест АСТ, баллы & $11,40 \pm 2,67$ & $11(9-13)$ & $17,6 \pm 3,9$ & $19(15-21)$ & $<0,001^{*}$ & $21,10 \pm 2,92$ & $22(20-23)$ & $<0,001^{* *}$ \\
\hline \multicolumn{9}{|c|}{ Опросник AQLQ } \\
\hline $\begin{array}{l}\text { Общее } \\
\text { количество баллов }\end{array}$ & $3,43 \pm 0,80$ & $3,15(2,9-3,9)$ & $4,22 \pm 1,06$ & $3,93(3,56-4,71)$ & $<0,001^{*}$ & $4,73 \pm 1,06$ & $4,31(3,9-5,7)$ & $0,02^{* *}$ \\
\hline Симптомы, баллы & $3,3 \pm 0,8$ & $3,27(2,75-3,75)$ & $4,23 \pm 1,10$ & $3,9(3,5-5,0)$ & $<0,001^{*}$ & $4,84 \pm 1,16$ & $4,62(3,75-6,16)$ & $0,027^{* *}$ \\
\hline $\begin{array}{l}\text { Ограничение } \\
\text { активности, баллы }\end{array}$ & $3,60 \pm 0,92$ & $3,36(2,81-4,27)$ & $4,40 \pm 1,08$ & $4,31(3,6-4,8)$ & $<0,001^{*}$ & $4,73 \pm 1,00$ & $4,5(3,9-5,27)$ & $0,027^{* *}$ \\
\hline $\begin{array}{l}\text { Эмоциональная } \\
\text { сфера, баллы }\end{array}$ & $3,52 \pm 1,15$ & $3,2(2,8-4,0)$ & $4,07 \pm 1,40$ & $3,7(2,8-5,4)$ & $0,029^{*}$ & $4,70 \pm 1,13$ & $4,3(4,0-6,0)$ & $0,027^{* *}$ \\
\hline $\begin{array}{l}\text { Влияние окружающей } \\
\text { среды, баллы }\end{array}$ & $3,30 \pm 1,03$ & $3(2,75-3,75)$ & $3,85 \pm 1,22$ & $3,25(3,00-4,25)$ & $0,019^{*}$ & $4,37 \pm 1,16$ & $4(3,50-5,25)$ & $0,043^{* *}$ \\
\hline
\end{tabular}

Примечание: * - статистически значимые различия по сравнению с исходными данными; ** - статистически значимые различия по сравнению с результатами, полученными через 16 нед. терапии.

симптомов $-2,17 \pm 0,88 ; 2$ (2-3) в неделю, частота ингаляций сальбутамола в сутки - 6,00 $\pm 1,31$; 6 (5-7), частота госпитализаций в год $-2,34 \pm 1,26$; 2 (2-3), частота внеплановых визитов к врачу $4,30 \pm 1,96 ; 4$ (3-5) в год. Частота обострений БА за прошедший год была также высокой и составила $3,95 \pm 1,18 ; 4$ (3-4). Количество баллов по результатам теста по контролю над БА составляло 11,56 \pm 2,17; 11 (10-13). Показатели качества жизни (AQLQ) у пациентов в группе сравнения были следующими: общий балл - 3,37 $\pm 0,45 ; 3,43(3,00-3,73)$, симптомы БА - 3,25 $\pm 0,55 ; 3,41(2,83-3,75)$ балла, ограничение повседневной активности $-3,57 \pm 0,50 ; 3,45$ $(3,1-4,0)$ балла, эмоциональная сфера $-3,35 \pm 0,67$; $3,6(2,8-3,8)$ балла, влияние окружающей среды $3,23 \pm 0,65 ; 3,25(2,75-3,50)$ балла.

Исходно статистических различий между группами выявлено не было.
Пациенты 1-й группы получали омализумаб в дополнение к проводимой базисной терапии, после 12 нед. лечения предпринимались попытки снизить дозу иГКС постепенно каждые 2 нед.: вначале до 1500 мкг в сутки, если текущая доза была > 1750 мкг в сутки, и на 250 мкг при текущей дозе < 1750 мкг в сутки.

Средняя доза омализумаба составила $371,73 \pm$ 142,08 мг в месяц.

Через 16 и 32 нед. лечения омализумабом отмечалось статистически значимое снижение количества дневных симптомов в неделю, которое составило $3,26 \pm 2,41 ; 2(2-7)$ и $2,0 \pm 2,6 ; 1,5(0-2)$ соответственно $(p<0,001)$. Отмечалось снижение количества ночных симптомов до $0,21 \pm 0,42 ; 0$ ( $p<0,001)$ к 16-й нед. терапии и до 0,16 \pm 0,40; 0 - к 32-й нед. Также статистически значимым было снижение потребности в ингаляциях $\beta_{2}$-агонистов $-2,56 \pm 2,08$;

Таблица 3 Динамика клинических и функциональных показателей у больных, получавших омализумаб

\begin{tabular}{|c|c|c|c|c|c|c|c|c|}
\hline \multirow{3}{*}{ Показатели } & \multicolumn{8}{|c|}{ Периоды наблюдения } \\
\hline & \multicolumn{2}{|c|}{ до начала лечения } & \multicolumn{3}{|c|}{16 нед. } & \multicolumn{3}{|c|}{ 32-44 нед. } \\
\hline & $\bar{X} \pm S$ & $\operatorname{Me}(25-75 \%)$ & $\bar{X} \pm S$ & $\operatorname{Me}(25-75 \%)$ & $p$ & $\bar{X} \pm S$ & $\operatorname{Me}(25-75 \%)$ & $p$ \\
\hline $\begin{array}{l}\text { Частота дневных } \\
\text { симптомов в неделю }\end{array}$ & $6,56 \pm 1,07$ & $7(7-7)$ & $3,26 \pm 2,41$ & $2(2-7)$ & $0,001^{*}$ & $2,0 \pm 2,6$ & $1,5(0-2)$ & \\
\hline $\begin{array}{l}\text { Частота ночных } \\
\text { симптомов в неделю }\end{array}$ & $2,04 \pm 1,55$ & $2(1-3)$ & $0,21 \pm 0,42$ & & 0,001 & $0,16 \pm 0,40$ & & \\
\hline $\begin{array}{l}\text { Частота ингаляций } \\
\text { сальбутамола в сутки }\end{array}$ & $5,90 \pm 2,71$ & $6(4-8)$ & $2,56 \pm 2,08$ & $2(1-2)$ & $<0,001^{*}$ & $1,33 \pm 1,96$ & $0,5(0-2)$ & $0,01^{* *}$ \\
\hline 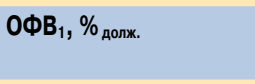 & $59,10 \pm 17,06$ & $\begin{array}{c}58 \\
(46,3-72,6)\end{array}$ & $84,2 \pm 18,1$ & $\begin{array}{c}88,3 \\
(72-98)\end{array}$ & $<0,001^{*}$ & $99,6 \pm 24,3$ & $\begin{array}{c}103 \\
(85,9-117,0)\end{array}$ & \\
\hline $\begin{array}{l}\text { Частота внеплановых } \\
\text { визитов к врачу в год }\end{array}$ & $3,95 \pm 1,77$ & $4(3-5)$ & - & - & - & $0,47 \pm 0,73$ & $0(0-1)$ & $<0,001^{*}$ \\
\hline $\begin{array}{l}\text { Частота обострений } \\
\text { в год }\end{array}$ & $4,39 \pm 2,36$ & $4(3-6)$ & - & - & - & $0,56 \pm 0,72$ & $0(0-1)$ & $<0,001^{*}$ \\
\hline $\begin{array}{l}\text { Частота госпитали- } \\
\text { заций в год }\end{array}$ & $1,47 \pm 0,84$ & $1(1-2)$ & - & - & - & $0,13 \pm 0,34$ & & $<0,001^{*}$ \\
\hline $\begin{array}{l}\text { Суточная } \\
\text { доза иГКС, мкг }\end{array}$ & $1552,1 \pm 534,1$ & $\begin{array}{c}2000 \\
(1000-2000)\end{array}$ & $1128,20 \pm 411,43$ & $\begin{array}{c}1000 \\
(1000-1500)\end{array}$ & $<0,001^{*}$ & $750,0 \pm 577,3$ & $\begin{array}{c}500 \\
(500-750)\end{array}$ & $0,043^{* *}$ \\
\hline
\end{tabular}

Примечание: * - статистически значимые различия по сравнению с исходными данными; ** - статистически значимые различия по сравнению с результатами, полученными через 16 нед. терапии. 
Таблица 4

Диналика клинических и функциональных показателей у больных группы сравнения

\begin{tabular}{|c|c|c|c|c|c|c|}
\hline \multirow{3}{*}{ Показатели } & \multicolumn{6}{|c|}{ Периоды наблюдения } \\
\hline & \multicolumn{2}{|c|}{ до начала лечения } & \multicolumn{2}{|c|}{16 нед. } & \multicolumn{2}{|c|}{ 32-44 нед. } \\
\hline & $\bar{x} \pm S$ & Me $(25-75 \%)$ & $\bar{X} \pm S$ & $\operatorname{Me}(25-75 \%)$ & $\bar{x} \pm S$ & $\operatorname{Me}(25-75 \%)$ \\
\hline $\begin{array}{l}\text { Частота дневных } \\
\text { симптомов в неделю }\end{array}$ & $6,65 \pm 0,71$ & $7(7-7)$ & $5,43 \pm 1,53$ & $6(2-7)$ & $5,73 \pm 1,76^{*}$ & $7(5-7)$ \\
\hline $\begin{array}{l}\text { Частота ночных } \\
\text { симптомов в неделю }\end{array}$ & $2,04 \pm 1,55$ & $2(1-3)$ & $1,78 \pm 1,04$ & $2(1-3)$ & $1,69 \pm 0,97$ & $2(1-2)$ \\
\hline $\begin{array}{l}\text { Частота ингаляций } \\
\text { сальбутамола в сутки }\end{array}$ & $6,00 \pm 1,31$ & $6(5-7)$ & $5,43 \pm 1,77$ & $6(4-7)$ & $5,39 \pm 1,92$ & $6(4-6)$ \\
\hline ОФВ ${ }_{1}, \%_{\text {долж. }}$ & $63,47 \pm 12,19$ & $67,9(56,4-73,8)$ & $63,56 \pm 15,16$ & $68(52,0-75,5)$ & $62,39 \pm 12,23$ & $64,5(49,9-73,7)$ \\
\hline Тест АСТ, баллы & $11,56 \pm 2,17$ & $11(10-13)$ & $11,52 \pm 3,84$ & $11(7-19)$ & $11,73 \pm 4,03$ & $10(9-14)$ \\
\hline \multicolumn{7}{|c|}{ Опросник AQLQ } \\
\hline $\begin{array}{l}\text { Общее количество } \\
\text { баллов }\end{array}$ & $3,37 \pm 0,45$ & $3,43(3,00-3,73)$ & $3,38 \pm 0,66$ & $3,4(3,0-3,9)$ & $3,37 \pm 0,56$ & $3,43(3,0-3,8)$ \\
\hline Симптомы, баллы & $3,25 \pm 0,55$ & $3,41(2,83-3,75)$ & $3,3 \pm 0,7$ & $3,4(2,9-3,9)$ & $3,34 \pm 0,70$ & $3,4(3,0-3,8)$ \\
\hline $\begin{array}{l}\text { Ограничение } \\
\text { активности, баллы }\end{array}$ & $3,57 \pm 0,50$ & $3,45(3,1-4,0)$ & $3,63 \pm 0,68$ & $3,45(3,0-4,1)$ & $3,54 \pm 0,57$ & $3,5(2,9-3,9)$ \\
\hline $\begin{array}{l}\text { Эмоциональная сфера, } \\
\text { баллы }\end{array}$ & $3,35 \pm 0,67$ & $3,6(2,8-3,8)$ & $3,20 \pm 1,13$ & $3,6(1,8-4,0)$ & $3,30 \pm 1,15$ & $3,6(2,4-4,0)$ \\
\hline $\begin{array}{l}\text { Влияние окружающей } \\
\text { среды, баллы }\end{array}$ & $3,23 \pm 0,65$ & $3,25(2,75-3,50)$ & $3,15 \pm 0,97$ & $3,25(2,5-3,5)$ & $3,11 \pm 0,78$ & $3,0(2,75-3,50)$ \\
\hline $\begin{array}{l}\text { Частота внеплановых } \\
\text { визитов к врачу в год }\end{array}$ & $4,30 \pm 1,96$ & $4(3-5)$ & - & - & $4,08 \pm 1,70$ & $4(3-5)$ \\
\hline $\begin{array}{l}\text { Частота обострений } \\
\text { в год }\end{array}$ & $3,95 \pm 1,18$ & $4(3-4)$ & - & - & $3,78 \pm 1,53$ & $4(3-5)$ \\
\hline $\begin{array}{l}\text { Частота госпитали- } \\
\text { заций в год }\end{array}$ & $3,95 \pm 1,18$ & $4(3-4)$ & - & - & $2,34 \pm 1,55$ & $2(1-3)$ \\
\hline
\end{tabular}
мкг

$1456,52 \pm 520,33 \quad 1500(1000-2000) \quad 1486,95 \pm 525,90 \quad 1200(1000-2000) \quad 1510,0 \pm 502,7 \quad 1500(1000-2000)$

Примечание: * - $><0,05$ по сравнению с исходным значением.

2 (1-2) при $p<0,001$ и $1,33 \pm 1,96 ; 0,5(0-2)$ при $p=0,01$ на 16-й и 32-й нед. лечения соответственно. Суточная доза иГКС составила на 16-й нед. лечения 1 128,2 \pm 411,4; 1000 (1 000-1 500) мкг при $p<0,001$ и 750,0 $\pm 577,3 ; 500(500-750)$ мкг при $p=0,043$ на 32-й нед. лечения (табл. 3).

За период дальнейшего наблюдения за пациентами, получавшими омализумаб, частота внеплановых визитов к врачу сократилась до $0,47 \pm 0,73 ; 0$ (0-1) при $p<0,001$, статистически значимыми были также снижение частоты госпитализаций по поводу ухудшения течения БА $(0,13 \pm 0,34 ; 0$ при $p<0,001)$ и снижение количества обострений $(0,56 \pm 0,72 ; 0$ (0-1) при $p<0,001)$. К 16-й нед. лечения отмечалось значительное улучшение бронхиальной проходимости, среднее значение ОФВ 1 составило 84,2 $\pm 18,1 ; 88,3$ (72-98) \% долж. $(p<0,001)$, на 32-й нед. значение данного показателя составило 99,6 \pm 24,3; 103 (85,9$117,0) \%_{\text {долж. }}$

Результаты теста по контролю над БА на 16-й нед. терапии составили $17,6 \pm 3,9 ; 19$ (15-21) баллов $(p<0,001)$, на 32-й нед. $-21,10 \pm 2,92 ; 22$ (20-23) балла $(p<0,001)$. Отмечалось значимое повышение качества жизни у пациентов, его показатели, по данным опросника AQLQ, на 16-й и 32-й нед. соответственно составили: общий балл $-4,22 \pm 1,06 ; 3,93$

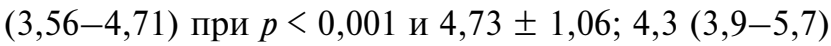
при $p=0,02$; симптомы БА - 4,23 $\pm 1,1 ; 3,9(3,5-5,0)$ балла при $p<0,001$ и 4,84 $\pm 1,16 ; 4,62(3,75-6,16)$ балла при $p=0,027$; ограничение повседневной активности $-4,40 \pm 1,08 ; 4,31(3,6-4,8)$ балла при $p<0,001$ и 4,73 $\pm 1,00 ; 4,5(3,9-5,2)$ балла при $p=0,027$; эмоциональная сфера $-4,07 \pm 1,40 ; 3,7(2,8-5,4)$ балла при $p=0,029$ и 4,70 $\pm 1,13 ; 4,3(4,0-6,0)$ балла при $p=0,027$; влияние окружающей среды $-3,85 \pm$ 1,$22 ; 3,25(3,00-4,25)$ балла при $p=0,019$ и 4,37 \pm 1,$16 ; 4(3,50-5,25)$ балла при $p=0,043$.

В 1-й группе на 16-й нед. лечения полный контроль над симптомами БА был достигнут у 7 больных $(30,4 \%)$, частично контролируемое течение было у 9 пациентов $(39,1 \%)$. На 32-й нед. терапии омализумабом полностью контролировать БА удалось у 11 больных (47,8 \%), частичный контроль был достигнут у 5 пациентов (21,7 \%), следовательно, улучшить контроль БА удалось в 69,6 \% случаев. Неконтролируемое течение БА сохранялось у 7 (30,4\%) пациентов на протяжении всего периода лечения.

Во 2-й группе зарегистрировано некоторое уменьшение количества дневных симптомов до 5,73 \pm 1,76; 7 (5-7) при $p=0,034$, однако не столь выраженное как в 1-й группе. В частоте ночных симптомов, количестве ингаляций сальбутамола в сутки не было отмечено статистически значимых различий по сравнению с исходными показателями. Сохранялось невысоким значение ОФВ принимать высокие дозы иГКС. Не было статистически значимых различий в показателях качества жизни, частоте внеплановых визитов в поликлинику, 
частоте обострений и госпитализаций, связанных с БА (табл. 4). К 16-й нед. течение заболевания было частично контролируемым у 2 больных $(8,6 \%)$, к 32-й нед. - у 3 (13,0 \%). Достигнуть полного контроля над симптомами БА в группе сравнения не удалось.

Из нежелательных явлений в группе пациентов, получавших омализумаб, у 2 больных были отмечены проявления ОРВИ, 1 пациент перенес острый фарингит. Во всех случаях отмены препарата не потребовалось. Во 2-й группе проявления ОРВИ зарегистрированы в 3 случаях.

\section{Заключение}

Таким образом, проведенное клиническое исследование показало, что применение омализумаба у пациентов с тяжелой неконтролируемой БА эффективно уменьшает выраженность симптомов заболевания, приводя к значимому улучшению качества жизни к 16 нед. лечения. В исследуемой группе больных показана безопасность и хорошая переносимость лечения омализумабом на протяжении 12 мес. терапии.

\section{Литература}

1. Beasley R., Crane J., Lai C.K., Pearce N. Prevalence and etiology of asthma. J. Allergy Clin. Immunok. 2000; 105: 466-472.

2. Global initiative for asthma (GINA). www.ginasthma.com

3. Принципы диагностики и лечения бронхиальной астмы в реальной клинической практике. Пульмонология и аллергология 2007; 3 (26): 3-10.

4. Фисенко В.П. Омализумаб (Ксолар): принципы действия, эффективность и безопасность. Пульмонология 2007; 5: 100-105.

5. Fick R.B. Jr. Anti-IgE as novel therapy for the treatment of asthma. Curr. Opin. Pulm. Med. 1999; 5: 76-80.

6. Noga O., Hanf G., Kunkel G. Immunological and clinical changes in allergic asthmatics following treatment with omalizumab. J. Int. Arch. Allergy Immunol. 2003; 131: 46-52.

7. MacGlashan D.W. Jr., Bochner B.S., Adelman D.C. et al. Down-regulation of human basophil IgE and FCepsilonRI alpha surface densities and mediator release by anti-IgEinfusions is reversible in vitro and in vivo. J. Immunol. 1999; 162: 5624-5630.

8. Hanf G., Brachmann I., Kleine-Tebbe J. et al. Omalizumab decreased IgE-release and induced changes in cellular imunity in patients with allergic asthma. Allergy 2006; 61: $1141-1144$
9. Noga O., Hanf G., Brachmann I. et al. Effect of omalizumab treatment on peripheral eosinophil and T-lymfocyte function in patients with allergic asthma. J. Allergy Clin. Immunol. 2006; 1493-1499.

10. Busse W., Corren J., Lanier B.Q. et al. Omalizumab, antiIgE recombinant humanized monoclonal antibody, for the treatment of severe allergic asthma. J. Allergy Clin. Immunol. 2001; 108 (2): 184-190.

11. Hendeles L., Sorkness C.A. Anti-immunoglobulin E therapy with omalizumab for asthma. Ann. Pharmacother. 2007; 41 (9): 1397-1410.

12. Solèr M., Matz J., Townley R. et al. The anti-IgE antibody omalizumab reduces exacerbations and steroid requirement in allergic asthmatics. Eur. Respir. J. 2001; 18 (2): 254-261.

13. Cruz A.A., Lima F., Sarinho E. et al. Safety of antiimmunoglobulin $\mathrm{E}$ therapy with omalizumab in allergic patients at risk of geohelminth infection. Clin. Exp. Allergy 2007; 37 (2): 197-207.

14. Limb S.L., Starke P.R., Lee C.E., Chowdhury B.A. Delayed onset and protracted progression of anaphylaxis after omalizumab administration in patients with asthma. J. Allergy Clin. Immunol. 2007; 120 (6): 1378-1381.

15. Lanier B.Q., Corren J., Lumry W. et al. Omalizumab is effective in the long-term control of severe allergic asthma. Ann. Allergy Asthma Immunol. 2003; 91 (2): 154-915.

16. Corren J., Shapiro G., Reimann J. et al. Allergen skin tests and free IgE levels during reduction and cessation of omalizumab therapy. J. Allergy Clin. Immunol. 2008; 121 (2): 506-511.

17. Belliveau P.P., Lahoz M.R. Evaluation of omalizumab from a health plan perspective. J. Manag. Care Pharm. 2005; 11 (9): 735-745.

18. Juniper E.F., Guyatt G.H., Ferrie P.J. et al. Measuring quality of life in asthma. Am. Rev. Respir. Dis. 1993; 147: 832-838.

19. Thomas M., Kay S., Pike J. et al. The Asthma Control Test (ACT) as a predictor of GINA guideline-defined asthma control: analysis of a multinational cross-sectional survey. Primary Care Respiratory J. 2009; 18 (1): 41-49.

\section{Информация об авторах}

Сучкова Юлия Борисовна - аспирант НИИ пульмонологии ФМБА России; тел.: (495) 965-41-32; e-mail: yuls11349@yandex.ru

Осипова Галина Леонидовна - д. м. н., ведущий научный сотрудник лаборатории клинической фармакологии НИИ пульмонологии ФМБА России; тел.: (495) 965-41-32; e-mail: osipovagl@bk.ru

Чучалин Александр Григорьевич - д. М. Н., проф., акад. РАМН, директор ФГУ НИИ пульмонологии ФМБА России; тел.: (495) 465-52-64

Пашкова Татьяна Леонидовна - к. М. Н., научный сотрудник лаборатории функциональных и ультразвуковых методов исследования НИИ пульмонологии ФМБА России; тел.: (495) 465-53-84

Поступила 18.05 .09 (с) Коллектив авторов, 2009 удК 616.248-085.234 